\title{
Penerapan Biaya Kualitas Dalam Meningkatkan Efisiensi Biaya Produksi Pada Catering ABC
}

\author{
Mustika Rahmi \\ Eka Rosalina \\ Irda Rosita \\ Politeknik Negeri Padang
}

\begin{abstract}
Abstrak
Persaingan dalam dunia usaha menuntut perusahaan untuk menghasilkan produk yang berkualitas. Dalam peningkatan kualitas itu sendiri menimbulkan biaya yang disebut biaya kualitas. Adapun tujuan dari penelitian ini adalah untuk mengetahui penerapan biaya kualitas dalam meningkatkan efisiensi biaya produksi pada Perusahaan Catering ABC Padang. Unsurunsur biaya kualitas pada umumnya ada empat akan tetapi biaya kualitas yang terdapat pada Catering $A B C$ Padang ada tiga unsur biaya kualitas yaitu, biaya pencegahan, biaya penilaian, biaya kegagalan eksternal, sedangkan biaya kegagalan internal tidak terdapat pada perusahaan. Biaya kualitas yang terbesar terjadi pada tahun 2014 sebesar Rp. 383.809.980 atau $3,14 \%$ dari total penjualan aktualnya. Dari hasil taksiran yang diperoleh dengan penambahan biaya pada kategori biaya pencegahan, biaya kualitas menurun sebesar Rp. 143.379.480 dibandingkan sebelumnya Rp.383.809.980 atau sebesar $1,13 \%$ dari total penjualan aktualnya, yang artinya terjadi penghematan biaya sebesar Rp. 240.430.480. Sehingga dapat disimpulkan dengan menetapkan biaya kualitas dapat meningkatkan efisiensi produksi karena adanya penekanan biaya secara keseluruhan.
\end{abstract}

Kata kunci: Kualitas, Biaya kualitas, Biaya produksi, Efisiensi biaya produksi

\section{PENDAhUluan}

Sebagai usaha catering yang sudah di kenal masyarakat umum kota Padang, Catering $A B C$ harus mampu menghadapi dan siap atas persaingan. Penjaminan kualitas makanan adalah salah satu komitmen Catering $\mathrm{ABC}$ terhadap konsumennya. Selain menjaga kualitas produknya ada dimensi lain yang harus di pertimbangkan, yaitu biaya produksi, dimana selain kualitas yang terjamin harga yang terjangkau adalah daya tarik tersendiri bagi sebuah usaha catering. Untuk mengatasi hal itu sebuah usaha harus mengeluarkan biaya produksi seefisien mungkin.

Kegiatan-kegiatan yang dilakukan perusahaan dalam meningkatkan kualitas produk di kenal dengan istilah "biaya kualitas". Ketika perusahaan menerapkan program perbaikan kualitas, timbul kebutuhan untuk memantau dan melaporkan program-program tersebut (Hansen dan
Mowen, 2009). Pelaporan dan pengukuran biaya kualitas sangatlah penting untuk keberhasilan program perbaikan kualitas yang sedang di jalankan suatu perusahaan, jadi penting bagi perusahaan untuk mengetahui dan melakukan pengukuran serta melaporkan biaya kualitas tersebut.

Dengan latar belakang ini, maka perumusan masalah dalam penelitian ini adalah :

1. Bagaimana dan apa saja aktifitas pengendalian kualitas yang diterapkan Catering $A B C$ ?

2. Biaya-biaya apa saja yang timbul dari pengendalian kualitas produk di Catering $A B C$ ?

3. Bagaimana penerapan biaya kualitas di Catering $A B C$ dapat meningkatkan efisiensi biaya produksi? 


\section{TINJAUAN PUSTAKA}

\subsection{Biaya Produksi}

Biaya produksi merupakan biaya-biaya yang terjadi untuk mengolah bahan baku menjadi produk jadi yang siap untuk dijual (Mulyadi, 2005). Contohnya adalah biaya bahan baku, biaya tenaga kerja, biaya depresiasi peralatan, dan lain-lain. Menurut objek pengeluarannya secara garis besar biaya produksi di bagi menjadi tiga bagian yaitu : biaya bahan baku, biaya tenaga kerja langsung dan biaya overhead pabrik.

\subsection{Defenisi Kualitas}

Secara umum, kamus mendefinisikan kualitas sebagai "derajat atau tingkat kesempurnaan". Dalam hal ini, kualitas adalah ukuran relatif dari kebaikan (goodness). Menurut Hansen dan Mowen (2009) kualitas didefinisikan tingkat atau nilai keunggulan; dalam arti, kualitas merupakan tolak ukur relatif terhadap kebaikan. Secara operasional, kualitas suatu produk atau jasa adalah sesuatu yang memenuhi atau melebihi harapan pelanggan. Jadi, kualitas adalah kepuasan pelanggan.

\subsection{Biaya Kualitas}

Menurut Hansen dan Mowen (2009:268) biaya kualitas dapat didefinisikan kegiatan yang berhubungan dengan kualitas adalah kegiatan yang dilakukan karena kualitas yang buruk, mungkin atau telah terjadi. Biaya-biaya untuk melakukan kegiatankegiatan ini disebut biaya kualitas. Jadi, biaya kualitas adalah biaya-biaya yang timbul karena mungkin atau atau telah terdapatnya produk dengan kualitas yang buruk.

\subsection{Penggolongan Biaya Kualitas}

Biaya kualitas digolongkan menjadi empat kategori:

a. Biaya pencegahan (Prevention cost)
Biaya pencegahan terjadi untuk menghindari kualitas yang buruk. Biaya pencegahan adalah biaya yang terjadi untuk menghalangi produksi dari produk yang tidak memenuhi spesifikasi.

b. Biaya penilaian (appraisal cost)

Biaya penilaian sebagai biaya yang terjadi untuk menditeksi unit individu mana yang tidak memenuhi spesifikasi.

c. Biaya kegagalan internal (internal failure cost)

Biaya kegagalan internal adalah biaya yang terjadi pada suatu produk yang cacat sebelum dikirim ke pelanggan.

d. Biaya kegagalan eksternal (eksternal failure cost)

Biaya kegagalan eksternal yaitu biaya yang dikeluarkan untuk memperbaiki kerusakan kualitas setelah produk atau jasa yang tidak dapat diterima mencapai pelanggan.

\subsection{Tujuan Biaya Kualitas}

Biaya kualitas disusun oleh perusahaan atas dasar suatu tujuan yang melandasi hal tersebut. Hansen dan Mowen (2009:272) mengungkapkan tujuan biaya kualitas sebagai berikut:

1. Memperbaiki dan mempermudah perencanaan, pengendalian, dan pengambilan keputusan manajerial.

2. Memproyeksikan mengenai kapan biaya dan penghematan itu terjadi dan dibuat. Jadi, tujuan pembuatan biaya kualitas adalah untuk mempermudah proses keputusan manajemen. Selain itu juga, agar perusahaan dapat memproyeksikan kapan biaya terjadi, serta agar perusahaan dapat mengefisiensikan biaya. Dengan adanya tujuan biaya kualitas, perusahaan mengharapkan agar biaya kualitas dapat dipergunakan dengan baik.

\subsection{Pelaporan Informasi Biaya Kualitas}

Suatu sistem pelaporan biaya kualitas menjadi penting (esensial) jika organisasi tersebut serius dengan biaya perbaikan dan pengontrolan kualitas. Langkah pertama dan 
sederhana dalam menciptakan sistem tersebut adalah dengan melaporkan biayabiaya kualitas aktual saat ini.

Daftar yang rinci dari biaya kualitas aktual per-kategori dapat memberikan dua informasi penting. Pertama, daftar ini menunjukkan beberapa yang di keluarkan untuk tiap kategori biaya kualitas dan pengaruhnya terhadap laba. Kedua, daftar tersebut menunjukkan distribusi biaya kualitas dengan kategori, memungkinkan para manajer menilai kepentingan relatif tiap kategori.

\subsection{Hubungan Biaya Kualitas dengan Efisiensi Biaya Produksi}

Biaya yang dikeluarkan untuk mengerjakan kembali produk yang gagal yang disebabkan karena pengendalian kualitas dari produk yang tidak baik atau yang tidak sesuai dengan spesifikasi standar kualitas yang telah ditetapkan, akan lebih besar dari pada biaya yang dikeluarkan untuk mencegah kegagalan produk tersebut terjadi.

Oleh karena itu, jika kegiatan pengendalian kualitas dapat berjalan dengan baik, tanpa menghasilkan produk cacat dalam proses produksi. Maka pengulangan kerja akan berkurang karena menurunnya unit produk cacat.

Hansen Mowen (2009:265) mengatakan bahwa: "Dengan menurunnya unit produk cacat maka sedikit tenaga kerja dan bahan yang digunakan untuk menghasilkan output yang sama. Penurunan jumlah unit cacat memperbaiki kualitas, sementara pengurangan jumlah input yang digunakan meningkatkan efisiensi produksi”.

Tabel 1

Penelitian Terdahulu

\begin{tabular}{|c|c|c|c|c|}
\hline No & Peneliti & $\begin{array}{l}\text { Judul } \\
\text { Penelitian }\end{array}$ & Metode & Hasil \\
\hline 1 & $\begin{array}{l}\text { Erviansyah } \\
\text { (2013) }\end{array}$ & $\begin{array}{l}\text { Analisis } \\
\text { Biaya } \\
\text { Kualitas } \\
\text { terhadap } \\
\text { produk cacat } \\
\text { pada PT } \\
\text { Nusa } \\
\text { Toyotetsu } \\
\text { Corporation }\end{array}$ & $\begin{array}{l}\text { Analisis } \\
\text { Deskriptif } \\
\text { Kuantitatif }\end{array}$ & 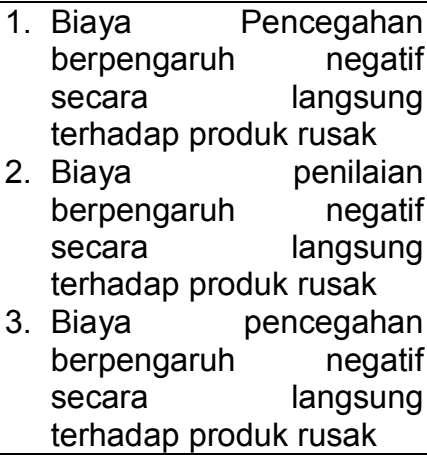 \\
\hline 1 & $\begin{array}{l}\text { Bawon, dkk } \\
\text { (2013) }\end{array}$ & $\begin{array}{l}\text { Penerapan } \\
\text { Biaya } \\
\text { Kualitas } \\
\text { untuk } \\
\text { Meningkatka } \\
\text { n Efisiensi } \\
\text { Biaya } \\
\text { produksi }\end{array}$ & Deskriptif & $\begin{array}{l}\text { Berdasarkan penelitian } \\
\text { yang dilakukan perusahaan } \\
\text { belum menerapkan dan } \\
\text { melaporkan biaya kualitas. } \\
\text { Walaupun belum } \\
\text { menerapkan dan } \\
\text { melaporkan biaya kualitas } \\
\text { terdapat kegiatan-kegiatan } \\
\text { yang berkaitan } \\
\text { dengan biaya kualitas.. }\end{array}$ \\
\hline
\end{tabular}




\begin{tabular}{|c|c|c|c|c|}
\hline No & Peneliti & $\begin{array}{l}\text { Judul } \\
\text { Penelitian }\end{array}$ & Metode & Hasil \\
\hline 3 & $\begin{array}{l}\text { Tulende } \\
\text { dan Ilat } \\
(2014)\end{array}$ & $\begin{array}{l}\text { Penerapan } \\
\text { Biaya } \\
\text { Kualitas } \\
\text { untuk } \\
\text { Meningkatka } \\
\text { n Efisiensi } \\
\text { Biaya } \\
\text { Produksi } \\
\text { pada UD. } \\
\text { Sinar Sakti } \\
\text { Manado }\end{array}$ & $\begin{array}{l}\text { deskriptif } \\
\text { kuantitatif }\end{array}$ & $\begin{array}{lr}\text { Hasil penelitian } \\
\text { menunjukkan bahwa } \\
\text { dengan menambah jumlah } \\
\text { karyawan pada saat } \\
\text { pemeriksaan bahan baku } \\
\text { dan pembantu, maka } \\
\text { kemungkinan adanya bahan } \\
\text { baku yang berkualitas } \\
\text { rendah menurun sehingga } \\
\text { produk yang dihasilkan } \\
\text { memiliki kualitas yang lebih } \\
\text { baik dan akan berdampak } \\
\text { pada jumlah penjualan yang } \\
\text { naik }\end{array}$ \\
\hline
\end{tabular}

\section{METODE PENELITIAN}

\subsection{Jenis Penelitian}

Penelitian ini menggunakan metode kualitatif bersifat deskriptif. Penelitian bersifat deskriptif bertujuan untuk membuat deskripsi, gambaran secara sistematis dan akurat mengenai fakta-fakta, sifat-sifat serta hubungan antar fenomena yang diteliti.

Penelitian ini menggunakan pendekatan studi kasus pada salah satu perusahaan di kota Padang (Catering $A B C$ ), data dikumpulkan melalui wawancara, observasi dan dokumentasi untuk menguraikan tentang sifat-sifat, aspek-aspek dan keadaan yang sebenarnya dari suatu obyek penelitian secara spesifik untuk memperoleh data.

\subsection{Jenis dan Sumber Data}

a. Data kuantitatif

Yaitu dokumen yang memuat data-data pendukung perhitungan, seperti laporan biaya operasional, rincian gaji karyawan, laporan pendapatan, laporan laba/rugi dan rincian aset tetap.

b. Data kualitatif

Yaitu data-data yang berupa sejarah perusahaan dan narasi proses produksi.

\subsection{Teknik Pengumpulan Data}

1. Penelitian Lapangan ( Field Research) yaitu penelitian yang dilakukan secara langsung, berupa :

a. Wawancara

Wawancara di lakukan dalam bentuk tidak terstruktur sehingga peneliti dapat menggali informasi lebih lanjut dan lebih lengkap. Wawancara di lakukan dengan mengajukan pertanyaan-pertanyaan mengenai kegiatan perusahaan dalam proses produksinya, bagaimana pengendalian kualitas produk di perusahaan, apa standar kualitas produk di perusahaan dan apa saja usaha perusahaan untuk menjaga serta meningkatkan kualitas produknya.

b. Observasi

Observasi dilakukan untuk mengamati dan mengawasi sendiri objek yang akan di teliti sehingga peneliti dapat mengetahui secara langsung kondisi perusahaan yang dijadikan sebagai objek penelitian. Observasi yang dilakukan oleh peneliti adalah mengamati proses produksi yang dilakukan perusahaan, mengamati peralatan dan sumber daya yang di gunakan dalam proses produksi. 
Penerapan Biaya Kualitas dalam Meningkatkan Efisiensi Biaya Produksi

c. Dokumentasi

Dokumentasi yang dilakukan yaitu dengan cara mengumpulkan data berupa sejarah perusahaan, laporan biaya operasional dan umum, laporan pendapatan, list gaji karyawan, rincian aset tetap, dan lain-lain.

2. Penelitian Perpustakaan (Library Reseach)

Yaitu penelitian yang dilakukan guna memperoleh pengetahuan dan landasan teori dari berbagai literatur, referensi dan hasil penelitian yang berhubungan dengan objek penelitian.

\section{HASIL PENELITIAN DAN PEMBAHASAN}

\subsection{Visi dan Misi Catering $A B C$}

Catering $A B C$ telah menetapkan visi yang merupakan arah tujuan jangka panjang yang hendak dicapai pada masa mendatang yaitu
"Menjadi industri jasa boga terbaik di Indonesia".

Untuk mewujudkan visi tersebut, maka Catering $A B C$ telah menetapkan misi sebagai berikut :

1. Menerapkan SMM ISO 9001-2008 dan management information system

2. Meningkatkan sumber daya manusia yang berkualifikasi yang profesional

3. Melengkapi sarana dan prasarana yang berkualifikasi berstandar catering

4. Menciptakan menu makanan dan minuman yang bercitarasa nasional dan internasional

5. Memberikan pelayanan sesuai dengan persyaratan pelanggan

6. Menciptakan lingkungan kerja kondusif yang berstandar catering.

\subsection{Hasil Penelitian}

Berdasarkan penelitian yang telah dilakukan terdapat kegiatan-kegiatan berupa biaya yang berhubungan dengan biaya kualitas, selama ini Catering $A B C$ belum melakukan pelaporan biaya kualitas secara khusus, laporan biaya kualitas tahun 2012-2014 adalah sebagai berikut :

Tabel 2.

Laporan biaya kualitas Catering ABC tahun 2012 (dalam rupiah)

\begin{tabular}{lrr}
\hline JENIS BIAYA & \multicolumn{1}{l}{ JUMLAH } & PERSENTASE \\
\hline Biaya pencegahan & & \\
Biaya SMM ISO 9001:2008 & 15.000 .000 & $4,33 \%$ \\
Biaya perbaikan dan peralatan produksi & 9.150 .000 & $2,64 \%$ \\
Biaya pendidikan dan pelatihan karyawan produksi & 2.575 .000 & $0,74 \%$ \\
\hline Jumlah biaya pencegahan & $\mathbf{2 6 . 7 2 5 . 0 0 0}$ & $\mathbf{8 \%}$ \\
\hline Biaya Penilaian & & \\
Biaya penilaian hasil produksi & 34.394 .500 & $9,94 \%$ \\
Biaya pemeriksaan bahan baku & 24.860 .000 & $\mathbf{7 , 1 8 \%}$ \\
\hline Jumlah biaya penilaian & $\mathbf{5 9 . 2 5 4 . 5 0 0}$ & $\mathbf{1 7 \%}$ \\
\hline Biaya kegagalan eksternal & & \\
Biaya penggantian bahan makanan & 260.064 .747 & $\mathbf{7 5 , 1 5 \%}$ \\
\hline Jumlah biaya kegagalan eksternal & $\mathbf{2 6 0 . 0 6 4 . 7 4 7}$ & $\mathbf{7 5 , 1 5 \%}$ \\
\hline TOTAL BIAYA KUALITAS & $\mathbf{3 4 6 . 0 4 4 . 2 4 7}$ & $\mathbf{1 0 0 \%}$ \\
\hline \hline Sumber $:$ data olahan & &
\end{tabular}


Penerapan Biaya Kualitas dalam Meningkatkan Efisiensi Biaya Produksi

Tabel 3.

Laporan Biaya kualitas Catering ABC tahun 2013 (dalam rupiah)

\begin{tabular}{lrr}
\hline JENIS BIAYA & JUMLAH & PERSENTASE \\
\hline Biaya pencegahan & & \\
Biaya SMM ISO 9001:2008 & 15.000 .000 & $4,39 \%$ \\
Biaya perbaikan dan peralatan produksi & 8.950 .000 & $2,62 \%$ \\
Biaya pendidikan dan pelatihan karyawan produksi & - & $0,00 \%$ \\
\hline Jumlah biaya pencegahan & $\mathbf{2 3 . 9 5 0 . 0 0 0}$ & $\mathbf{7 \%}$ \\
\hline Biaya Penilaian & & \\
Biaya penilaian hasil produksi & 34.782 .500 & $10,17 \%$ \\
Biaya pemeriksaan bahan baku & 24.860 .000 & $\mathbf{7 , 2 7 \%}$ \\
\hline Jumlah biaya penilaian & $\mathbf{5 9 . 6 4 2 . 5 0 0}$ & $\mathbf{1 7 \%}$ \\
\hline Biaya kegagalan eksternal & & \\
Biaya penggantian bahan makanan & 258.304 .608 & $\mathbf{7 5 , 5 5 \%}$ \\
\hline Jumlah biaya kegagalan eksternal & $\mathbf{2 5 8 . 3 0 4 . 6 0 8}$ & $\mathbf{7 5 , 5 5 \%}$ \\
\hline TOTAL BIAYA KUALITAS & $\mathbf{3 4 1 . 8 9 7 . 1 0 8}$ & $\mathbf{1 0 0 \%}$ \\
\hline \hline
\end{tabular}

Sumber : data olahan

Tabel 4

Laporan Biaya kualitas Catering ABC tahun 2014 (dalam rupiah)

\begin{tabular}{lrr}
\hline JENIS BIAYA & JUMLAH & PERSENTASE \\
\hline Biaya pencegahan & - & $0,00 \%$ \\
Biaya SMM ISO 9001:2008 & 9.025 .000 & $2,35 \%$ \\
Biaya perbaikan dan peralatan produksi & 400.000 & $0,10 \%$ \\
Biaya pendidikan dan pelatihan karyawan produksi & $\mathbf{9 . 4 2 5 . 0 0 0}$ & $\mathbf{2 \%}$ \\
\hline Jumlah biaya pencegahan & & $10,21 \%$ \\
\hline Biaya Penilaian & 39.204 .500 & $7,65 \%$ \\
Biaya penilaian hasil produksi & 29.350 .000 & $\mathbf{1 8 \%}$ \\
Biaya pemeriksaan bahan baku & $\mathbf{6 8 . 5 5 4 . 5 0 0}$ & \\
\hline Jumlah biaya penilaian & & $79,68 \%$
\end{tabular}

30 Jurnal Akuntansi \& Manajemen Vol 10 No. 1 Juni 2015. ISSN 1858-3687 hal 25-35 
Penerapan Biaya Kualitas dalam Meningkatkan Efisiensi Biaya Produksi

\begin{tabular}{lrr}
\hline JENIS BIAYA & JUMLAH & \multicolumn{1}{l}{ PERSENTASE } \\
\hline & 305.830 .480 & \\
\hline Jumlah biaya kegagalan eksternal & $\mathbf{3 0 5 . 8 3 0 . 4 8 0}$ & $\mathbf{7 9 , 6 8 \%}$ \\
\hline TOTAL BIAYA KUALITAS & $\mathbf{3 8 3 . 8 0 9 . 9 8 0}$ & $\mathbf{1 0 0 \%}$ \\
\hline \hline
\end{tabular}

Sumber : data olahan

Tabel 5

Laporan biaya kualitas tahun 2012-2014

\begin{tabular}{llll} 
JENIS BIAYA & $\mathbf{2 0 1 2}$ & $\mathbf{2 0 1 3}$ & $\mathbf{2 0 1 4}$ \\
\hline $\begin{array}{l}\text { Biaya pencegahan } \\
\text { Biaya SMM ISO 9001:2008 }\end{array}$ & 15.000 .000 & 15.000 .000 & - \\
$\begin{array}{l}\text { Biaya perbaikan dan peralatan produksi } \\
\text { Biaya pendidikan dan pelatihan } \\
\text { karyawan produksi }\end{array}$ & 9.150 .000 & 8.950 .000 & 9.025 .000 \\
\hline Jumlah biaya pencegahan & 2.575 .000 & - & 400.000 \\
\hline Biaya Penilaian & $\mathbf{2 6 . 7 2 5 . 0 0 0}$ & $\mathbf{2 3 . 9 5 0 . 0 0 0}$ & $\mathbf{9 . 4 2 5 . 0 0 0}$ \\
$\begin{array}{l}\text { Biaya penilaian hasil produksi } \\
\text { Biaya pemeriksaan bahan baku }\end{array}$ & 34.394 .500 & 34.782 .500 & 39.204 .500 \\
\hline Jumlah biaya penilaian & 24.860 .000 & 24.860 .000 & 29.350 .000 \\
\hline Biaya kegagalan eksternal & $\mathbf{5 9 . 2 5 4 . 5 0 0}$ & $\mathbf{5 9 . 6 4 2 . 5 0 0}$ & $\mathbf{6 8 . 5 5 4 . 5 0 0}$ \\
\hline Biaya penggantian bahan makanan & 260.064 .747 & 258.304 .608 & 305.830 .480 \\
\hline Jumlah biaya kegagalan eksternal & $\mathbf{2 6 0 . 0 6 4 . 7 4 7}$ & $\mathbf{2 8 7 . 4 3 9 . 9 8 4}$ & $\mathbf{3 0 5 . 8 3 0 . 4 8 0}$ \\
\hline TOTAL BIAYA KUALITAS & $\mathbf{3 4 6 . 0 4 4 . 2 4 7}$ & $\mathbf{3 7 1 . 0 3 2 . 4 8 4}$ & $\mathbf{3 8 3 . 8 0 9 . 9 8 0}$ \\
\hline \hline
\end{tabular}

Sumber: Data Olahan

Tabel 6

Persentase biaya kualitas 2012-2014

\begin{tabular}{lccc}
\hline Jenis Biaya & $\mathbf{2 0 1 2}$ & $\mathbf{2 0 1 3}$ & $\mathbf{2 0 1 4}$ \\
\hline Biaya pencegahan & $7,7 \%$ & $6,5 \%$ & $2,5 \%$ \\
Biaya penilaian & $17,1 \%$ & $16,1 \%$ & $17,9 \%$ \\
Biaya kegagalan eksternal & $75,2 \%$ & $77,5 \%$ & $79,7 \%$ \\
\hline TOTAL & $\mathbf{1 0 0 , 0 \%}$ & $\mathbf{1 0 0 , 0 \%}$ & $\mathbf{1 0 0 , 0 \%}$ \\
\hline \hline
\end{tabular}

Setelah melakukan penelitian di Catering ABC, peneliti juga menemukan bahwa selama ini Catering $A B C$ belum mengelompokkan biaya produksi berdasarkan tiga kategori pada umumnya, biaya produksi masih tergabung pada biaya operasional dan umum, untuk itu peneliti mencoba mengelompokkan biaya tersebut 
Penerapan Biaya Kualitas dalam Meningkatkan Efisiensi Biaya Produksi

seperti laporan yang di sajikan dalam tabel berikut ini :

Tabel 7

Laporan Biaya Produksi Catering ABC tahun 2012-2014 (dalam rupiah)

\begin{tabular}{lcccrrr}
\hline & \multicolumn{2}{c}{$\mathbf{2 0 1 2}$} & & $\mathbf{2 0 1 3}$ & \multicolumn{1}{c}{$\mathbf{2 0 1 4}$} \\
\hline Biaya Bahan Baku & $\mathrm{Rp}$ & 6.276 .283 .431 & $\mathrm{Rp}$ & 5.702 .861 .244 & $\mathrm{Rp}$ & 6.092 .525 .109 \\
Biaya tenaga kerja langsung & $\mathrm{Rp}$ & 447.010 .000 & $\mathrm{Rp}$ & 462.520 .000 & $\mathrm{Rp}$ & 515.308 .000 \\
Biaya overhead pabrik & $\mathrm{Rp}$ & 1.404 .843 .430 & $\mathrm{Rp}$ & 1.175 .948 .337 & $\mathrm{Rp}$ & 1.086 .214 .254 \\
\hline TOTAL BIAYA PRODUKSI & $\mathrm{Rp} \mathbf{8 . 1 2 8 . 1 3 6 . 8 6 1}$ & $\mathrm{Rp} 7.341 .329 .581$ & $\mathrm{Rp} 7.694 .047 .363$ \\
\hline \hline
\end{tabular}

Berdasarkan aturan ibu jari (the rule of thump) bahwa biaya kualitas harus tidak lebih dari 2,5\% pertahun di hitung dari total penjualan pertahun (Hansen dan Mowen : 2001). Menentukan efisiensi biaya kualitas di lakukan dengan membandingkan biaya kualitas terhadap penjualan. Tujuan

penjualan adalah untuk mengetahui perusahaan membutuhkan upaya perbaikan atau tidak, karena di katakan bahwa biaya kualitas yang efisien adalah apabila total biaya kualitas lebih kecil dari 2,5\% jika di bandingkan dengan total penjualan. pembandingan biaya kualitas terhadap

Tabel 8

Perbandingan biaya kualitas dengan penjualan (dalam rupiah)

\begin{tabular}{ccccccccc}
\hline Tahun & & Penjualan & \multicolumn{2}{c}{$\begin{array}{c}\text { Biaya } \\
\text { pencegahan }\end{array}$} & Biaya penilaian & $\begin{array}{c}\text { Biaya kegagalan } \\
\text { eksternal }\end{array}$ \\
\hline 2012 & $\mathrm{Rp}$ & 13.687 .618 .286 & $\mathrm{Rp}$ & 26.725 .000 & $\mathrm{Rp}$ & 59.254 .500 & $\mathrm{Rp}$ & 260.064 .747 \\
2013 & $\mathrm{Rp}$ & 12.300 .219 .406 & $\mathrm{Rp}$ & 23.950 .000 & $\mathrm{Rp}$ & 59.642 .500 & $\mathrm{Rp}$ & 287.439 .984 \\
2014 & $\mathrm{Rp}$ & 12.233 .219 .205 & $\mathrm{Rp}$ & 9.425 .000 & $\mathrm{Rp}$ & 68.554 .500 & $\mathrm{Rp}$ & 305.830 .480 \\
\hline
\end{tabular}

Sumber : data olahan

Tabel 9

Persentase biaya kualitas terhadap penjualan

\begin{tabular}{cccccc}
\hline Tahun & Penjualan & $\begin{array}{c}\text { Biaya } \\
\text { pencegahan }\end{array}$ & $\begin{array}{c}\text { Biaya } \\
\text { penilaian }\end{array}$ & $\begin{array}{c}\text { Biaya } \\
\text { kegagalan } \\
\text { eksternal }\end{array}$ & TOTAL \\
\hline 2012 & Rp 13.687.618.286 & $0,20 \%$ & $0,43 \%$ & $1,90 \%$ & $2,53 \%$ \\
2013 & $\operatorname{Rp~} 12.300 .219 .406$ & $0,19 \%$ & $0,48 \%$ & $2,34 \%$ & $3,02 \%$ \\
2014 & Rp 12.233.219.205 & $0,08 \%$ & $0,56 \%$ & $2,50 \%$ & $3,14 \%$ \\
\hline
\end{tabular}

Sumber : data olahan

\subsubsection{Taksiran biaya kualitas}

Menurut Hansen dan Mowen (2001) pandangan tradisional terhadap kualitas adalah bahwa terdapat pertukaran antara biaya kontrol (biaya pencegahan dan biaya penilaian) dan biaya kegagalan (biaya kegagalan internal dan eksternal).

Hal ini merupakan perbandingan optimal antara biaya pengendalian dan biaya kegagalan, serta mewakili apa yang dikenal dengan tingkat kualitas yang dapat di terima (acceptable quality level-AQL). Biaya kualitas 
Penerapan Biaya Kualitas dalam Meningkatkan Efisiensi Biaya Produksi

tahun 2012-2014 menunjukkan bahwa biaya kegagalan eksternal (eksternal failure cost) akan mengalami penurunan seiring dengan meningkatnya biaya pencegahan (prevention cost).

Berdasarkan penelitian yang telah di lakukan, peneliti menemukan bahwa sebagian besar biaya kegagalan eksternal yang di keluarkan perusahaan adalah dari biaya penggantian makanan yang merupakan complain pelanggan atas produk perusahaan. Complain tersebut sering berupa makanan yang tidak bisa di konsumsi (basi), menanggapi complain tersebut biasanya perusahaan melakukan tindakan ganti rugi berupa uang atau mengganti dengan makanan yang baru.

Tabel 10

Taksiran biaya kualitas tahun 2014 (dalam rupiah)

\begin{tabular}{lrr}
\hline \multicolumn{1}{c}{ JENIS BIAYA } & \multicolumn{2}{c}{ PERSENTAS } \\
\hline Biaya pencegahan & & \\
Biaya SMM ISO 9001:2008 & 15.000 .000 & $0,12 \%$ \\
Biaya perbaikan dan peralatan produksi & 9.025 .000 & $0,07 \%$ \\
Biaya pendidikan dan pelatihan karyawan \\
produksi & 10.800 .000 & $0,09 \%$ \\
\hline Jumlah biaya pencegahan & $\mathbf{3 4 . 8 2 5 . 0 0 0}$ & $\mathbf{0 , 2 8 \%}$ \\
\hline Biaya Penilaian & & \\
Audit kualitas & 16.000 .000 & $0,13 \%$ \\
Biaya penilaian hasil produksi & 39.204 .500 & $0,32 \%$ \\
Biaya pemeriksaan bahan baku & 29.350 .000 & $0,24 \%$ \\
\hline Jumlah biaya penilaian & $\mathbf{8 4 . 5 5 4 . 5 0 0}$ & $\mathbf{0 , 6 9 \%}$ \\
\hline Biaya kegagalan eksternal & & \\
Biaya penggantian bahan makanan & 24.000 .000 & $0,20 \%$ \\
\hline Jumlah biaya kegagalan eksternal & $\mathbf{2 4 . 0 0 0 . 0 0 0}$ & $\mathbf{0 , 2 0} \%$ \\
\hline TOTAL BIAYA KUALITAS & $\mathbf{1 4 3 . 3 7 9 . 5 0 0}$ & $\mathbf{1 , 1 7 \%}$ \\
\hline \hline
\end{tabular}

Tabel 11

Perbandingan atara biaya kualitas aktual dan taksiran tahun 2014

\begin{tabular}{|c|c|c|c|}
\hline JENIS BIAYA & AKTUAL & TAKSIRAN & $\begin{array}{c}\text { PENAMBAHAN } \\
\text { (PENGURANGAN) }\end{array}$ \\
\hline \multicolumn{4}{|l|}{ Biaya pencegahan } \\
\hline $\begin{array}{l}\text { Biaya SMM ISO 9001:2008 } \\
\text { Biaya perbaikan dan }\end{array}$ & - & 15.000 .000 & $(15.000 .000)$ \\
\hline $\begin{array}{l}\text { peralatan produksi } \\
\text { Biaya pendidikan dan }\end{array}$ & 9.025 .000 & 9.025 .000 & - \\
\hline pelatihan karyawan produksi & 400.000 & 10.800 .000 & $(10.400 .000)$ \\
\hline
\end{tabular}




\begin{tabular}{|c|c|c|c|}
\hline JENIS BIAYA & AKTUAL & TAKSIRAN & $\begin{array}{l}\text { PENAMBAHAN } \\
\text { (PENGURANGAN) }\end{array}$ \\
\hline Jumlah biaya pencegahan & 9.425 .000 & 34.825 .000 & $(25.400 .000)$ \\
\hline \multicolumn{4}{|l|}{ Biaya Penilaian } \\
\hline Audit kualitas & - & 16.000 .000 & $(16.000 .000)$ \\
\hline $\begin{array}{l}\text { Biaya penilaian hasil produksi } \\
\text { Biaya pemeriksaan bahan }\end{array}$ & 39.204 .500 & 39.204 .500 & - \\
\hline baku & 29.350 .000 & 29.350 .000 & - \\
\hline Jumlah biaya penilaian & 68.554 .500 & 84.554 .500 & $(16.000 .000)$ \\
\hline $\begin{array}{l}\text { Biaya kegagalan eksternal } \\
\text { Biaya penggantian bahan } \\
\text { makanan }\end{array}$ & 305.830 .480 & 24.000 .000 & 281.830 .480 \\
\hline $\begin{array}{l}\text { Jumlah biaya kegagalan } \\
\text { eksternal }\end{array}$ & 305.830 .480 & 24.000 .000 & 281.830 .480 \\
\hline TOTAL BIAYA KUALITAS & 383.809 .980 & 143.379 .500 & 240.430 .480 \\
\hline
\end{tabular}

Sumber : Data olahan

Setelah di lakukan taksiran biaya kualitas, biaya kualitas Catering $A B C$ menurun sebesar $\mathrm{Rp} 240.430 .480,00$ membuat sehingga menjadikan biaya kualitas Catering
$A B C$ lebih efisien dan mampu mencapai persentase di bawah 2,5\%, Efisiensi Biaya tersebut di sajikan dalam tabel di bawah ini

Tabel 12

Persentase Efisiensi Biaya

\begin{tabular}{lrrrr}
\hline \multicolumn{1}{c}{ JENIS BIAYA } & \multicolumn{1}{c}{$\mathbf{2 0 1 4}$} & \multicolumn{1}{c}{ TAKSIRAN } & EFISIENSI & \% PENJUALAN \\
\hline Biaya kualitas & 378.109 .980 & 137.679 .500 & 240.430 .480 & $3,09 \%$ \\
$\begin{array}{l}\text { Penjualan tahun } \\
2014\end{array}$ & 12.233 .219 .205 & 12.233 .219 .205 & & $1,13 \%$ \\
& & & & \\
\hline \hline
\end{tabular}

\section{KESIMPULAN}

1. Setelah di lakukan penelusuran terhadap biaya produksi, Catering XX memiliki 3 macam biaya kualitas, yaitu biaya pencegahan (prevention cost), Biaya penilaian (appraisal cost dan biaya kegagalan eksternal (eksternal failure cost).

2. Berdasarkan penelitian yang telah di lakukan, penulis menemukan bahwa sebagian besar biaya kegagalan eksternal yang di keluarkan perusahaan adalah dari biaya penggantian makanan yang merupakan complain pelanggan atas produk perusahaan. Complain tersebut sering berupa makanan yang tidak bisa di konsumsi (basi), untuk meminimalisir hal ini perusahaan harus mengeluarkan biaya pencegahan berupa pelatihan dan pendidikan karyawan produksi untuk mempelajari bagaimana agar hal ini dapat di hindari dengan penanganan yang tepat.

3. Setelah penelitian ini di lakukan secara keseluruhan, maka dapat di simpulkan bahwa dengan penerapan biaya kualitas dapat memberikan banyak manfaat bagi manajemen perusahaan, dalam hal ini perusahaan dapat menjadikan biaya kualitas sebagai dasar untuk pengambilan keputusan produksi dan 
Penerapan Biaya Kualitas dalam Meningkatkan Efisiensi Biaya Produksi

menilai dampak biaya kualitas terhadap komponen keuangannya.

\section{DAFTAR REFERENSI}

Bawon,dkk.(2013).Penerapan Biaya Kualitas Untuk Meningkatkan Efisiensi Biaya Produksi : Studi kasus pada PT. Pertani (Persero) Cabang Sulawesi Utara. Jurnal Riset Akuntansi Going ConcernFEB UNSRAT.Universitas Sam Ratulangi Manado.

Hansen, Don R. dan Maryanne M. Mowen.(2009).Akuntansi Manjerial EdisiKedelapan Jilid 1.Jakarta:Salemba Empat.

Hansen, Don R. dan Maryanne M. Mowen.(2009).Akuntansi Manjerial Edisi kedelapan Jilid 2.Jakarta:Salemba Empat.

Hansen, Don R. dan Maryanne M. Mowen.(1997).Manajemen Biaya Buku 2. Jakarta:Salemba Empat.

Mulyadi.(2005).Akuntansi biaya,(pp. 116).Yogyakarta:Akedemi manajemen perusahaan YKPN.

Ratag,dkk. (2013). Penerapan Biaya Kualitas dalam Menigkatkan Efisiensi Biaya Produksi : Studi kasus pada PT. Tropica Cocoprima. Jurnal Riset Akuntansi Going Concern FEB UNSRAT. Universitas Sam Ratulangi Manado 